\title{
Corrigendum: bla Plasmids Circulating in Escherichia coli From Norwegian Broiler Production Are Related, but Distinguishable
}

\author{
Solveig Sølverød Mo ${ }^{1 * t}$, Amar Anandrao Telke ${ }^{1 \dagger}$, Kingsley Oteng Osei ${ }^{1,2 \neq}$, Camilla Sekse ${ }^{1}$, \\ Jannice Schau Slettemeås ${ }^{1}$, Anne Margrete Urdahl ${ }^{1}$, Hanna Karin llag ${ }^{3}$, \\ Thongpan Leangapichart ${ }^{1}$ and Marianne Sunde ${ }^{1}$ \\ ${ }^{1}$ Section for Food Safety and Animal Health Research, Department of Animal Health, Welfare and Food Safety, Norwegian \\ Veterinary Institute, Oslo, Norway, ${ }^{2}$ Faculty of Chemistry, Biotechnology and Food Science, Norwegian University of Life \\ Sciences, Ås, Norway, ${ }^{3}$ Section for Microbiology, Department of Analysis and Diagnostics, Norwegian Veterinary Institute, \\ Oslo, Norway
}

Approved by: Frontiers Editorial Office,

Frontiers Media SA, Switzerland

*Correspondence:

Solveig Sølverød Mo

solveig.mo@vetinst.no

tThese authors have contributed equally to this work

¥Present address: Kingsley Oteng Osei, Section for Pathology, Department of Analysis and Diagnostics, Norwegian

Veterinary Institute, Os/o, Norway

Specialty section:

This article was submitted to

Antimicrobials, Resistance and

Chemotherapy,

a section of the journal

Frontiers in Microbiology

Received: 24 June 2021 Accepted: 28 June 2021

Published: 16 July 2021

Citation:

Mo SS, Telke AA, Osei KO, Sekse C

Slettemeås JS, Urdahl AM, llag HK,

Leangapichart $T$ and Sunde M (2021)

Corrigendum: blacTX-M-1/Inc/1-1/

Plasmids Circulating in Escherichia coll

From Norwegian Broiler Production

Are Related, but Distinguishable.

Front. Microbiol. 12:730152.

doi: 10.3389/fmicb.2021.730152

\section{A Corrigendum on}

bla $a_{\mathrm{CTX}-\mathrm{M}-1} /$ IncI1-I $\gamma$ Plasmids Circulating in Escherichia coli From Norwegian Broiler Production Are Related, but Distinguishable

by Mo, S. S., Telke, A. A., Osei, K. O., Sekse, C., Slettemeås, J. S., Urdahl, A. M., et al. (2020). Front. Microbiol. 11:333. doi: 10.3389/fmicb.2020.00333

In the published article, there was an error in affiliation 1. Instead of "Section for Food Safety and Animal Health Research, Department of Animal Helath, Welfare and Food Safety, Norwegian Veterinary Institute, Oslo, Norway," it should be "Section for Food Safety and Animal Health Research, Department of Animal Health, Welfare and Food Safety, Norwegian Veterinary Institute, Oslo, Norway."

In the original article, there was an error. The accession number for the raw Illumina reads of the 31 E. coli isolates was missing.

A correction has been made to Materials and Methods, Sequence Analysis and Characterization, paragraph number 4 .

Complete plasmid sequences are available in GenBank; MN419430 (p17437), MN419431 (p19138), MN419432 (p21254), MN419433 (p20426), MN419434 (21249), MN419435 (p14263), MN419436 (p22440), MN419437 (p22638), and MN419438 (p24003). Raw reads for the 31 E. coli isolates are available from ENA (bioproject number PRJEB45077).

The authors apologize for this error and state that this does not change the scientific conclusions of the article in any way. The original article has been updated.

Copyright $\odot 2021$ Mo, Telke, Osei, Sekse, Slettemeås, Urdahl, Ilag, Leangapichart and Sunde. This is an open-access article distributed under the terms of the Creative Commons Attribution License (CC BY). The use, distribution or reproduction in other forums is permitted, provided the original author(s) and the copyright owner(s) are credited and that the original publication in this journal is cited, in accordance with accepted academic practice. No use, distribution or reproduction is permitted which does not comply with these terms. 